\title{
O processo de implementação da integração lavoura-pecuária-floresta na percepção dos produtores rurais do estado de Mato Grosso
}

\author{
The process of crop-livestock-forestry integration implementation in the \\ perception of rural producers from the state of Mato Grosso
}

\author{
Ana Cristina Peron Domingues ${ }^{1 *}$, Marco Antonio Camillo de Carvalho ${ }^{1}$, \\ Raimundo Nonato Cunha de França ${ }^{1}$
}

\begin{abstract}
RESUMO
Os resultados de décadas de impactos da "moderna agricultura" apareceram, em maior ou menor grau, nas desigualdades sociais, exclusão, êxodo rural, concentração de terras e degradação ambiental. Para a mitigação de tal problemática, algumas estratégias vêm sendo pesquisadas, desenvolvidas e transferidas aos produtores rurais, dentre estas a Integração Lavoura-Pecuária-Floresta (iLPF) que adentrou na política nacional por meio do Plano Setorial para a Consolidação de uma Economia de Baixa Emissão de Carbono na Agricultura em 2009, conhecido como Plano ABC, e tornou-se uma política pública sob a Lei 12.805, sancionada em 2013. A partir da perspectiva de que as políticas públicas precisam ser compreendidas muito além de uma intervenção do Estado em situações consideradas problemáticas, mas como interação entre este e a sociedade, o estudo teve como objetivo analisar a percepção dos produtores rurais do estado de Mato Grosso sobre o processo de implementação da iLPF. Para isso, utilizou-se a pesquisa descritivaexploratória com abordagem qualitativa. Na coleta dos dados foi aplicada a entrevista com o auxílio de um roteiro semiestruturado a 07 (sete) produtores rurais do estado de Mato Grosso que adotaram esse sistema de produção.
\end{abstract}

Palavras-chave: Sistema de produção; Política pública; Ambiente; Agricultura; Pecuária.

\begin{abstract}
The results of decades of impacts of "modern agriculture" appeared, to a greater or lesser extent, in social inequalities, exclusion, rural exodus, land concentration and environmental degradation. To mitigate this problem, some strategies have been researched, developed and transferred to rural producers, among them the Crop-Livestock-Forest Integration (iLPF) that entered the national policy through the Sectorial Plan for the Consolidation of a Low Economy Carbon Emission in Agriculture in 2009, known as the ABC Plan, and became a public policy under Law 12.805, enacted in 2013. From the view that public policies need to be understood far beyond State intervention in situations considered problematic, but as an interaction between that and the society, the study aimed to analyze the perception of rural producers in the State of Mato Grosso about the process of implementing the ILPF. For this, descriptive-exploratory research with a qualitative approach was used. In the data collection, the interview was applied with the aid of a semi-structured script to 07 (seven) rural producers in the State of Mato Grosso who adopted this production system.
\end{abstract}

${ }^{1}$ Universidade do Estado de Mato Grosso - Unemat. *E-mail: ana.peron@ unemat.br 
Keywords: Production system; Public policy; Environment; Agriculture; Livestock.

\section{INTRODUÇÃO}

O longo processo de evolução das agriculturas praticadas pelas sociedades, a organização social no entorno destas e o papel do Estado transcrevem a relação da humanidade com os recursos naturais, os sistemas de produção e os impactos causados por estes. Os resultados, não obstante, apareceram na contemporaneidade, em maior ou menor grau, nas desigualdades sociais, exclusão, êxodo rural, concentração de terras e degradação ambiental (MAZOYER; ROUDART, 2010).

Tomemos como ponto de partida para essa análise a chamada "moderna agricultura", por intermédio da "Revolução Verde", que introduziu nos países em desenvolvimento o pensamento da modernização do meio rural com a adoção do pacote tecnológico, visando o desenvolvimento da pesquisa em melhoramento genético, uso intensivo de agroquímicos e mecanização, cujo resultado não tardou a aparecer, culminando em preocupações ligadas a aspectos socioeconômicos e ambientais.

No Brasil, a década de 1950 marcou a entrada dessa modernização, embora o aumento da produtividade para sanar o problema da fome, objetivo engendrado na época (ABRAMOVAY, 1996), ocorreu mais pela expansão da fronteira agrícola, sobretudo no Cerrado se comparado ao incremento tecnológico. A partir daí, viu-se um ramo de atividade considerado importante fonte geradora de divisas e uma "crescente integração subordinada ao setor industrial e financeiro" (AGUIAR; MONTEIRO, 2005, p. 163).

Tal fenômeno, cujos impactos negativos passaram despercebidos num primeiro momento, aos olhos do governo e dos próprios produtores rurais, começa a dar sinal de transtornos e leva a "manifestações de contestação ao padrão técnico e econômico implementado pelas políticas agrícolas fortemente subsidiadas pelo Estado" (BRANDENBURG, 2005, p. 51). O autor complementa ainda que surgem, a partir da intensa modernização agrária, questionamentos sobre o padrão de desenvolvimento baseado na predominância da razão instrumental, vinda de grupos organizados. 
As contestações que iniciaram em nível local ultrapassaram fronteiras e passaram a fazer parte de análises e discussões globais. Nesse contexto, a Conferência das Nações Unidas sobre o Meio Ambiente Humano, realizada em Estocolmo em 1972, torna-se o marco inicial para estas discussões. A partir deste fato houve diversos acordos e conferências internacionais com foco nessa temática. Cabe destacar duas importantes conferências, ambas ocorridas no Brasil, a Eco-92 e a Rio+20.

A Conferência das Nações Unidas Sobre o Meio Ambiente e Desenvolvimento (CNUMAD) em 1992 no Rio de Janeiro, conhecida como Eco-92, institucionalizou a expressão "desenvolvimento sustentável" e abriu caminho para ações conjuntas, resultando na criação de organizações governamentais (Ministérios, Agências e outros) responsáveis por questões inerentes ao meio ambiente, com a multiplicação de legislações mais rigorosas. Tal evento abriu espaço também para a expansão e profissionalização das organizações ambientalistas, que passaram a ser percebidas e a se destacar nos Conselhos da ONU, participando de eventos oficiais com status consultivo a partir da Conferência das Nações Unidas sobre Desenvolvimento Sustentável em 2012, a Rio+20 (DIAS, 2011; GUIMARÃES, 2013; SILVA e ALCÂNTARA, 2015).

No Brasil, uma das ações advém do acordo voluntário assumido na $15^{\mathrm{a}}$ Conferência das Partes (COP 15) realizada em Copenhague em 2009, em que o país se comprometeu a reduzir a emissão dos gases de efeito estufa (GEE) até 2020. Para isso, foi criado o Plano Setorial para a Consolidação de uma Economia de Baixa Emissão de Carbono na Agricultura, conhecido como Plano ABC, instituído em 2009 e previsto na Política Nacional sobre Mudanças do Clima (MAPA, 2012), sendo uma de suas estratégias a Integração Lavoura-Pecuária-Floresta (iLPF), que se tornou uma política nacional sancionada em 2013 por meio da Lei 12.805, que estabelece os objetivos e princípios de implementação e execução do processo (BRASIL, 2013).

A iLPF foi inclusa no Plano ABC por ser um sistema produtivo que possui a capacidade de englobar benefícios e contribuições tecnológicas, econômicas e sociais, ecológicas e ambientais (BALBINO; BARCELLO; STONE, 2011) com uma perspectiva de ampliação para 4 milhões de hectares em todo o território nacional até 2020 (MAPA, 2012).

Esse sistema tem como objetivo a "intensificação do uso da terra, fundamenta-se na integração espacial e temporal dos componentes do sistema produtivo para atingir patamares cada vez mais elevados de qualidade do produto, qualidade ambiental e 
competitividade", além de diminuir a emissão de GEE sem desacelerar a produção no campo, e tem a possibilidade de ser adotado em pequenas, médias ou grandes propriedades rurais (BALBINO; BARCELLOS; STONE, 2011, p. 15).

Grande parte dos ganhos em produtividade na agropecuária brasileira se deve aos investimentos em ciência e tecnologia, com destaque para a Empresa Brasileira de Pesquisa Agropecuária - Embrapa (BARROS, 2010), a qual assume o protagonismo das pesquisas em iLPF no país, ao lado de parceiros importantes, representantes das instituições do terceiro setor e da iniciativa privada, o que ocorre por meio dos projetos de pesquisa, validação e transferência de tecnologias (EMBRAPA, 2015).

Por ser a iLPF uma política pública alicerçada nessas pesquisas e de outras instituições, como as universidades e organizações não-governamentais, consta na fase de implementação do Plano ABC a responsabilidade dos estados por meio da instituição de Grupos Gestores (MAPA, 2012) e da Lei 12.805/13, que veio para fortalecer esse processo.

Os envolvidos na implementação precisam garantir que as ações citadas sejam efetivadas e os resultados dos estudos cheguem até aqueles que de fato irão implantar esse sistema de produção. A partir desse contexto, o estudo teve como objetivo analisar a percepção dos produtores rurais do estado de Mato Grosso acerca desse processo, uma vez que, como enfatiza Di Giovanni (2009), as políticas públicas precisam ser compreendidas não apenas como uma intervenção do Estado em situações consideradas problemáticas, mas sim, como uma interação entre este e a sociedade.

Os valores presentes na percepção do ser humano, advindos da sua cultura, história, vivências, classe social, entre outros, fazem com que cada indivíduo expresse pensamentos e atitudes diferentes, levando-o a reagir também de forma diferente, seja em suas relações ou sobre o meio (SIMÕES; TIEDEMANN, 1985; OKAMOTO, 2002). Rodrigues et al (2012) pontuam que a compreensão da percepção, da sociedade ou de um grupo, sobre os problemas em seu entorno ou ações governamentais pode ser um instrumento valioso a disposição dos tomadores de decisão.

Dessa forma, a fase de implementação, visualizada como um processo, perpassa a compreensão, julgamento e reflexão do produtor rural e, uma vez conhecidos, contribuirão com a ampliação e/ou redirecionamentos de estratégias de ação. 


\section{Procedimentos Metodológicos}

O estudo teve como recorte metodológico central a pesquisa de natureza descritiva-exploratória, com abordagem qualitativa, que possibilitou a compreensão de questões muito particulares, e de um espaço mais profundo das relações do processo e do fenômeno em estudo (MINAYO, 2003). Nesse sentido, procurou-se explicitar a percepção dos produtores rurais acerca do tema com pretensão de investigar.

A pesquisa foi realizada com produtores rurais do estado de Mato Grosso, que está localizado na região Centro-Oeste do território brasileiro. Possui aproximadamente 3.035.122 habitantes (IBGE, 2010) e ocupa uma área de 903.202.446 km² (IBGE, 2016). A região é a terceira maior em extensão territorial do país e é a única a possuir características de três biomas: Pantanal, Cerrado e Amazônia.

A forma como foi realizada a ocupação em Mato Grosso conferiu-lhe uma característica de concentração de terras alicerçada no latifúndio monocultor e a criação extensiva de gado bovino. Primeiramente, as atividades eram voltadas ao extrativismo, introduzindo posteriormente a pecuária e a lavoura de subsistência (MENDES, 2012). Apenas no final da década de 1970 observaram-se transformações no ambiente agropecuário, acompanhando a tendência do agro nacional, o que implicou na diferenciação das características básicas do agro mato-grossense "tanto pelas inovações mecânicas, físico-químicas e biológicas, quanto por novos processos organizativos e gerenciais" (PEREIRA et al., 2006, p. 45).

Para conhecer a amplitude do tema em estudo, foi realizada primeiramente uma pesquisa bibliográfica e entrevista com pesquisador da Embrapa Agrosilvipastoril (Unidade situada em Sinop - MT).

A seleção dos sujeitos entrevistados ocorreu por meio de amostragem não probabilística por acessibilidade, em razão de não haver informações sobre quantos e quais seriam os produtores que trabalham com o Sistema iLPF em Mato Grosso, no período do estudo 2016/2017.

As características apresentadas dos aspectos econômicos de Mato Grosso contribuem para a existência de médias e grandes propriedades, embora em menor número, mas ocupando maior área. Assim, são nesses estabelecimentos rurais que a iLPF está sendo implantada e que foram foco do estudo. 
Com a finalidade de abranger diferentes áreas do território do estado, foi utilizada a divisão macrorregional (Polos Agroeconômicos) proposta pelo Instituto Mato-Grossense de Economia Agropecuária (IMEA) que segmenta o estado em sete macrorregiões: Noroeste, Norte, Nordeste, Médio-Norte, Oeste, Centro-Sul e Sudeste (IMEA, 2016). Portanto, foi entrevistado um produtor rural por região (Figura 1).

Para preservar a identidade dos entrevistados, optou-se por identificar os produtores rurais pelo número de ordem das entrevistas.

Para a coleta dos dados foi aplicada entrevista com o auxílio de um roteiro semiestruturado contendo 32 perguntas abertas e fechadas. A primeira parte apresentou questões acerca do perfil dos produtores e caracterização das propriedades rurais; na segunda parte buscou-se levantar dados sobre a caracterização do sistema iLPF a partir da percepção dos entrevistados com foco em seu conhecimento sobre o sistema, motivações e desafios para a implantação e acesso as políticas públicas. Após, foi realizada a análise dos dados e extraídas as informações para a qualificação dos resultados.

Figura 1- Localização da área e dos entrevistados do estudo

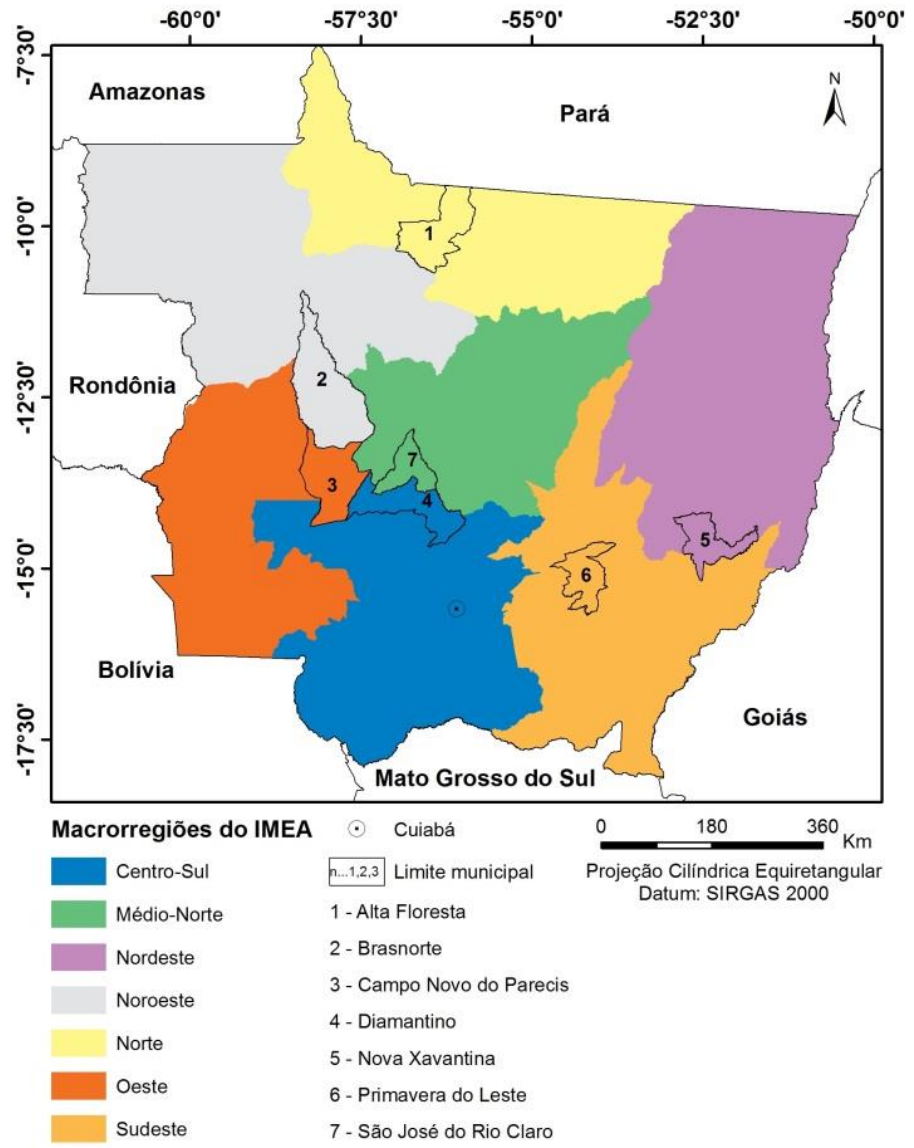

Fonte: Adaptado de IMEA (2016) 
A pesquisa foi previamente autorizada pelo Comitê de Ética em Pesquisa (CEP) da Universidade do Estado de Mato Grosso/Unemat, através do Parecer n. 1.509.446.

\section{Resultados e Discussão}

\section{Caracterização do produtor rural e do estabelecimento agrícola}

As características do produtor rural são significativas para a implementação de tecnologias e melhoria contínua de sistemas de produção. Neste item, além das características, são identificados também os motivos que levaram os entrevistados a empreenderem no segmento rural e os planos para o futuro no que tange ao estabelecimento agrícola.

Observou-se, a partir do estudo, a predominância do sexo masculino, sendo $100 \%$ da amostra. Tal fato, relacionado às atividades produtivas rurais quando se trata das situações de comando, é reforçado em outros estudos de Camarano e Abramovay (1999); Magalhães (2009) e Silva e Schneider (2010).

Verificou-se uma predominância também de migrantes da região sul do país, 71,4\% dos produtores, especialmente do estado do Paraná que, segundo Cunha (2006), nas décadas de 1970 e 1980, representavam 35\% do total de migração para o estado de Mato Grosso. Fato ocorrido em decorrência da modernização da agricultura nessa região que acarretou na "expulsão" dos produtores e na busca pelas regiões centrais do país (SWAIN, 1988), aliada a introdução da soja em Mato Grosso na década de 1980 (SANCHEZ, 1992). Assim, "se o estado do Paraná e outras regiões viviam um momento de "expulsão", o estado de Mato Grosso vivia um movimento de "atração" dessa mão de obra ligada ao trabalho no campo [...]" (CUSTÓDIO, 2015, p. 42).

A experiência dos entrevistados na atividade rural, todas acima de 20 anos, sugere uma vivência perpassada por várias transformações ocorridas no espaço agrário brasileiro e, especialmente, mato-grossense. São "frutos", como tantos outros, de uma política governamental que buscou a expansão agropecuária no Cerrado, com a produção voltada à exportação, por meio da adoção do padrão tecnológico da "Revolução Verde". Embora envolvidos nesse sistema, foi possível constatar o perfil diferenciado de conhecimento e pensamento a respeito dos impactos deixados de herança por esse modo de produção. 
Constatou-se que o fato de todos serem proprietários dos estabelecimentos agrícolas, é forte condição para se readequarem, planejarem e investirem em novas tecnologias, como a iLPF.

O estudo mostrou também a forte adesão dos grandes produtores do estado ao cooperativismo e associativismo, o que lhes permite, dentre os benefícios, um contato facilitado com a informação, as novidades e mudanças do meio, ao mesmo tempo em que estas instituições favorecem a difusão de informações oriundas dos produtores, por meio do compartilhamento de experiências.

Os dados podem ser observados na Tabela 1 a seguir.

Tabela 1: Distribuição das variáveis relacionadas às características dos produtores rurais

\begin{tabular}{|c|c|c|c|c|c|c|c|}
\hline $\begin{array}{c}\text { Produtor } \\
\text { Rural }\end{array}$ & Sexo & $\begin{array}{l}\text { Naturali- } \\
\text { dade }\end{array}$ & $\begin{array}{c}\text { Grau de } \\
\text { Escolaridade }\end{array}$ & $\begin{array}{c}\text { Tempo na } \\
\text { Atividade } \\
\text { Rural }\end{array}$ & $\begin{array}{c}\text { Condição } \\
\text { do Produtor }\end{array}$ & $\begin{array}{l}\text { Associado a } \\
\text { Sindicato }\end{array}$ & Associado \\
\hline 1 & Masc. & Paraná & $\begin{array}{c}\text { Ensino Médio } \\
\text { Completo }\end{array}$ & 30 Anos & Proprietário & $\begin{array}{l}\text { Sindicato } \\
\text { Rural }\end{array}$ & $\begin{array}{c}\text { Cooperativa } \\
\text { C.Vale }\end{array}$ \\
\hline 2 & Masc. & Paraná & $\begin{array}{l}\text { Ensino Superior } \\
\text { Completo }\end{array}$ & 20 Anos & Proprietário & $\begin{array}{c}\text { Sindicato } \\
\text { Rural } \\
\text { Sindicato } \\
\text { Madeireiro } \\
\end{array}$ & $\begin{array}{l}\text { Associação } \\
\text { Arefloresta }^{2}\end{array}$ \\
\hline 3 & Masc. & Paraná & $\begin{array}{c}\text { Ensino Superior } \\
\text { Completo }\end{array}$ & 48 Anos & Proprietário & $\begin{array}{c}\text { Sindicato } \\
\text { Rural }\end{array}$ & $\begin{array}{c}\text { Cooperativa } \\
\text { C.Vale }\end{array}$ \\
\hline 4 & Masc. & Paraná & $\begin{array}{c}\text { Ensino Superior } \\
\text { Completo }\end{array}$ & 23 Anos & Proprietário & $\begin{array}{c}\text { Sindicato } \\
\text { Rural } \\
\end{array}$ & $\begin{array}{c}\text { Associação } \\
\mathrm{Ampa}^{3}\end{array}$ \\
\hline 5 & Masc. & São Paulo & $\begin{array}{c}\text { Ensino } \\
\text { Fundamental } \\
\text { Completo }\end{array}$ & 32 Anos & Proprietário & $\begin{array}{l}\text { Sindicato } \\
\text { Rural }\end{array}$ & $\begin{array}{c}\text { Cooperativa } \\
\text { Caap }^{4}\end{array}$ \\
\hline 6 & Masc. & Goiás & $\begin{array}{c}\text { Ensino Superior } \\
\text { Completo }\end{array}$ & 25 Anos & Proprietário & $\begin{array}{l}\text { Sindicato } \\
\text { Rural }\end{array}$ & $\begin{array}{l}\text { Associação } \\
\text { Aprosoja }^{5}\end{array}$ \\
\hline 7 & Masc. & $\begin{array}{l}\text { Rio Grande } \\
\text { do Sul }\end{array}$ & $\begin{array}{l}\text { Ensino Médio } \\
\text { Incompleto }\end{array}$ & 20 Anos & Proprietário & $\begin{array}{l}\text { Sindicato } \\
\text { Rural }\end{array}$ & $\begin{array}{c}\text { Associação } \\
\text { ABCZ }^{6} \\
\text { Cooperativa } \\
\text { Primacred }^{7}\end{array}$ \\
\hline
\end{tabular}

Fonte: Dados da pesquisa

Nota: ${ }^{1}$ C.Vale - Cooperativa Agroindustrial; ${ }^{2}$ Associação de Reflorestadores de Mato Grosso; ${ }^{3}$ Associação Mato-grossense dos Produtores de Algodão; ${ }^{4}$ Cooperativa Aliança dos Produtores do Parecis; ${ }^{5}$ Associação dos Produtores de Soja e Milho do Estado de Mato Grosso; ${ }^{6}$ Associação Brasileira dos Criadores de Zebu; ${ }^{7}$ Cooperativa de Crédito Rural de Primavera do Leste.

Quando indagados se as atividades rurais, especialmente o Sistema iLPF, são financiadas, todos os entrevistados afirmaram utilizar de capital próprio e, cinco destes $(71,4 \%)$, utilizam também financiamento externo, oriundos especialmente do Banco do Brasil e Banco Bradesco. Sicredi, Rabobank e Cooperativa C. Vale apareceram uma vez nos relatos. Dos cinco produtores que disseram utilizar financiamento externo, apenas três deles se enquadraram no financiamento do Programa $\mathrm{ABC}$ e todos via fonte de investimento do Banco do Brasil.

Observa-se que essa prática do custeio próprio, principalmente em relação a soja em Mato Grosso, vem diminuindo. Na safra 2015/2016, foi praticada por $40 \%$ dos 
produtores do estado, já na safra 2018/2019 essa porcentagem baixou para 20\%, sendo que o sistema financeiro, empresas multinacionais, bancos com recursos federais e revendas de insumos e implementos agrícolas complementaram o restante do custeio (IMEA, 2015; 2019). O IMEA esclarece que a tendência é de maior participação dos recursos livres dos bancos, diminuindo a porcentagem dos bancos com recursos federais. Isso se deve à descapitalização do produtor rural que se recupera das dificuldades de safras anteriores e assim precisa recorrer ao mercado para financiar $80 \%$ de seu custeio.

Os dados demonstram a estrutura financeira que se estabelece no entorno do médio e grande produtor e proporciona capacidade para adequação às mudanças, que são, de alguma forma, exigidas para a continuidade de suas atividades.

Na sequência são apresentadas as características dos estabelecimentos agrícolas dos entrevistados em que a área total destinada à produção confirma os entrevistados como médios ou grandes produtores. Isso se deve à histórica concentração fundiária no estado, especialmente a partir do novo processo de ocupação na década de $1940 \mathrm{em}$ apoio ao Programa "Marcha para o Oeste", uma tentativa de conquistar o interior do país para integrá-lo à economia nacional (MORENO, 1993).

O estudo demonstra que a principal lavoura cultivada pelos pesquisados é a soja, produto que foi introduzido no estado de mato Grosso na década de 1980, ocupando na época uma área de 70.431 mil/ha (SÁNCHEZ, 1992), e que chegou à safra 2015/2016 a 9.140 milhões/ha, com 26.058,1 milhões/tons (CONAB, 2016), sendo estimado um incremento de 2,8\% de área de produção, atingindo 10.284,2 milhões/ha a safra 2020/2021 como continuidade do processo de expansão no estado (CONAB, 2020). Por ser a soja amplamente fomentada pelo governo federal pela sua representatividade no equilíbrio da balança comercial, acarreta um olhar diferenciado ao médio e grande produtor.

Quanto ao modelo de sistema iLPF implantado, não foi encontrado nenhum modelo completo, mas sim os sistemas agropastoril (agricultura e pecuária) e silvipastoril (floresta e pecuária). De acordo com os entrevistados, isso se deve a escassez de mão-de-obra especializada para conduzir as três atividades conjuntamente (agricultura, pecuária e floresta) e igualmente, carência de assistência técnica, além do alto investimento e retorno a longo prazo, o que não é atrativo para muitos produtores. Salientam, ainda, que é preciso enquadrar a modalidade adotada ao perfil da região e do 
produtor. Os relatos são corroborados por Balbino, Barcellos e Stone (2011) ao afirmarem que ainda existem limitações quando se fala da expansão da iLPF no Cerrado, como ausência de linhas de crédito, infraestrutura e logística.

A evolução das áreas implantadas com a iLPF, pelos pesquisados, mostra um aumento significativo. Número que, para muitos, ainda deve aumentar, pois em relação aos planos para o futuro do estabelecimento rural, $71,4 \%$ dos produtores responderam que pretendem expandir a produção.

Os dados descritos, evolução da área implantada, a modalidade de integração adotada e as atividades econômicas desenvolvidas podem ser conferidos na Tabela 2 .

Tabela 2: Distribuição das variáveis relacionadas às características dos estabelecimentos agrícolas

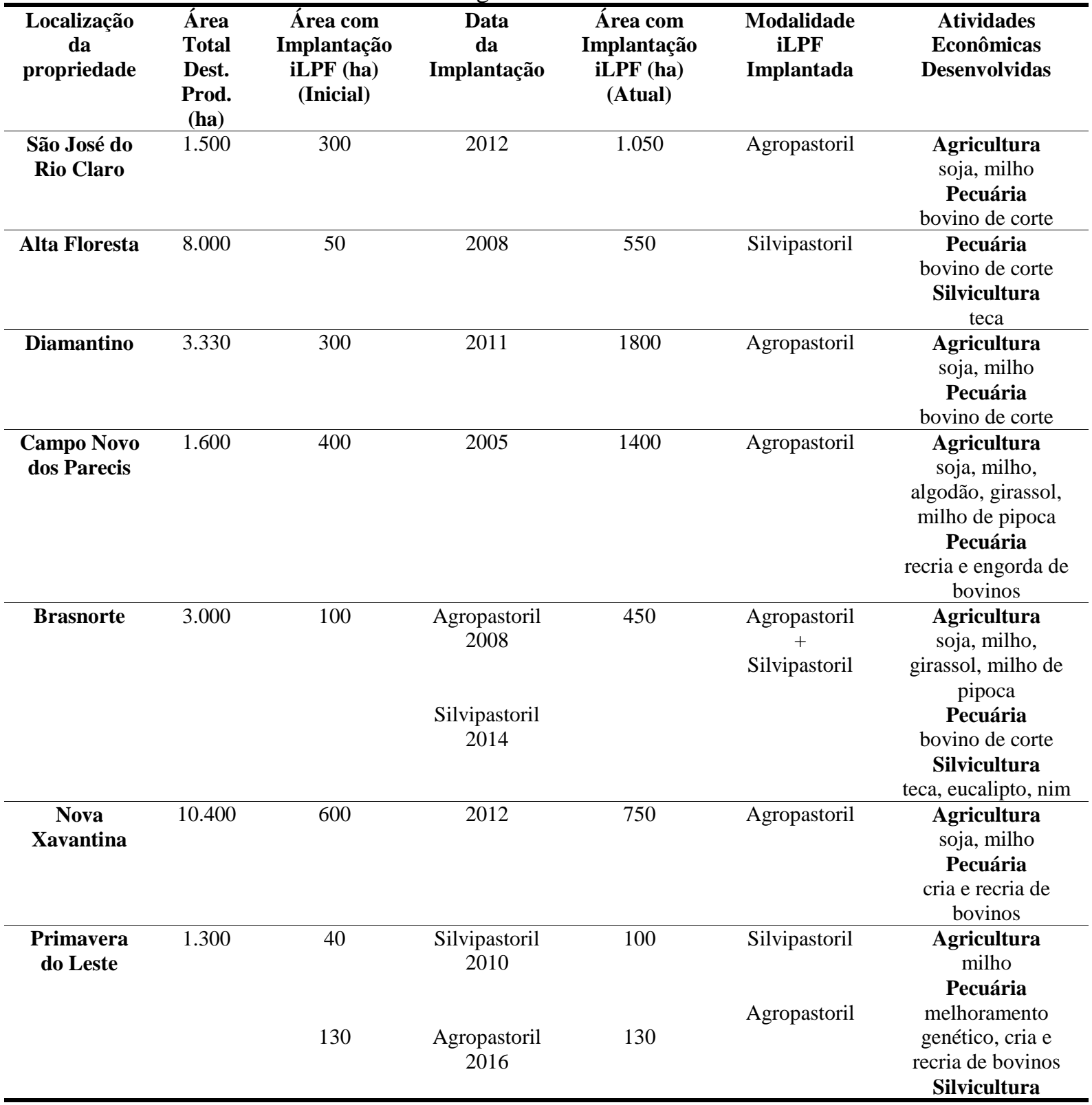


Fonte: Dados da pesquisa

\section{Informação e comunicação como canais para a implementação do sistema iLPF}

A comunicação com o produtor rural por meio das instituições ligadas ao segmento, sejam governamentais, não governamentais ou privadas, e a aquisição de informações foram identificados como elementos condutores imprescindíveis no sucesso da implementação da iLPF no estado.

Em relação às informações sobre o tema iLPF, existe uma uniformidade quanto aos meios pelos quais os produtores as obtiveram. A Universidade foi citada por um produtor; eventos na modalidade "Dia de Campo" citados por dois produtores; quatro produtores relataram obter informações por meio do Canal Rural. Foram citados, também, a internet, os assessores técnicos e a Revista DBO.

A partir dos relatos, observa-se uma sociedade de mudanças rápidas, em que a construção da informação e comunicação são importantes veículos para os avanços no campo da ciência e tecnologia. Verifica-se o importante papel e poder que os meios de comunicação desempenham ao trazer informações especializadas que possam efetivamente subsidiar tomadas de decisão. Para Tilman et al (2002), os produtores precisam ser munidos de incentivos e conhecimentos apropriados para tomadas de decisão mais eficientes em relação às ações que possam impactar de forma positiva os recursos naturais.

Dentre as informações recebidas pelos entrevistados a respeito da iLPF, há também aquelas relacionadas ao Plano $\mathrm{ABC}$, embora nem todos afirmaram conhecerem-no. Assim, apenas quatro produtores relataram conhecer bem suas ideias, condições de financiamento e a documentação necessária para o acesso ao crédito.

Ao serem abordados sobre a participação em eventos após a implantação da iLPF na unidade produtiva, nos quais esta fez parte da pauta, cinco produtores disseram terem participado de até dois eventos anuais. Os demais relataram não ter sido a iLPF assunto de nenhum dos eventos que participaram.

Os dados apresentados demonstram, até o momento do seu levantamento, que o Plano ABC ainda não havia sido amplamente divulgado no estado. Pode-se inferir que em razão da recente adesão de Mato Grosso, em 2013 (MATO GROSSO, 2013), foram 
insipientes suas ações até 2016, quando houve uma redefinição do Grupo Gestor, com um novo planejamento e redirecionamento para as mesmas.

Pode-se observar que o conhecimento construído por meio da participação ativa e da vivência possibilitou aos produtores empreenderem no processo de implementação do Sistema iLPF e, posteriormente, adequar e desenvolver seus sistemas próprios de manejo de acordo com a realidade da unidade produtiva. Em relação ao manejo, apenas dois produtores enfatizaram que buscaram junto a Embrapa o suporte para aplicar o Sistema. As falas a seguir transcrevem suas experiências:

\footnotetext{
Foi tudo implantado por iniciativa própria (Produtor 1).

Fizemos todo o manejo sozinhos e depois de implantado o Sistema, passamos a receber visitas dos professores e alunos da Unemat, UFMT e Embrapa (Produtor 2).

Foi implantado por conta própria, apenas com assessoria do técnico [...] quanto à transferência de tecnologia, na verdade não está havendo ajuda de ninguém, o agricultor está implantando sozinho (Produtor 3 ).

Fui em busca das informações junto aos pesquisadores da Embrapa, a qual deu o suporte (Produtor 4).

Participei de palestras e outros eventos [...] após, chamei os pesquisadores da Embrapa para participarem da implantação [...] nos tornamos uma URT da Embrapa, colaborando com outros produtores (Produtor 5).

$\mathrm{O}$ apoio veio somente da consultoria privada que fez o projeto para o Programa $\mathrm{ABC}$ e trabalharam o manejo (Produtor 6).

[...] busquei as informações e fiz a implantação. [...] sempre recebo alunos de universidades para visita de campo (Produtor 7).
}

Verifica-se, a partir das falas, que a concepção de mundo do produtor leva-o a constituir um corpo de conhecimento, o qual é transferido para o plano de manejo e, consequentemente, irá estruturar o sistema de produção adotado, ou seja, a técnica se torna uma expressão da visão de mundo dos produtores, motivo pelo qual diferentes formas de manejo são adotadas. Isso significa que os produtores estão se adaptando à mudança do monocultivo para a integração sem muita dependência dos conhecimentos especializados, o que favorece a implementação. Por outro lado, as pesquisas e a assistência técnica capacitadas viabilizam uma tomada de decisão mais assertiva e, portanto, a redução do tempo de implementação desse processo.

$\mathrm{Na}$ percepção dos pesquisados, a relação de aproximação entre algumas instituições (implementadores) e o produtor rural é bastante deficitária no estado. Todavia, instituições como a Embrapa e Famato apareceram em todas as observações feitas pelos produtores como sendo as que participaram mais efetivamente em Mato Grosso.

Para Carvalho e Montaño (2012), fica evidente que o alcance do desenvolvimento sustentável, discutido a nível global, só é possível quando o 
planejamento das políticas for pensado de forma a integrá-las, o que pode ser feito, de acordo com Stead e Meijers (2009), de maneira horizontal (entre os diversos setores e domínios políticos), bem como verticalmente (entre os atores políticos e as diferentes escalas de governança).

\section{Percepção dos produtores sobre os benefícios e contribuições da iLPF}

Em um primeiro momento os produtores foram questionados sobre os motivos que os levaram a adotar a iLPF. Para cinco destes produtores, trata-se do retorno financeiro com o aumento da produtividade. A diminuição da incidência de erosão em solo arenoso; manutenção da fertilidade do solo; e para não ficar na dependência de apenas uma atividade foram justificativas dadas mais de uma vez pelos entrevistados. Outros motivos podem ser encontrados na Tabela 3.

Tabela 3: Distribuição dos motivos que levaram os entrevistados a adotarem o Sistema iLPF.

\begin{tabular}{llc}
\hline Motivos & $\mathbf{N}^{*}$ & $\mathbf{\%}$ \\
\hline Retorno financeiro com o aumento da produtividade & 05 & 71,40 \\
Diminuir a incidência de erosão em solo arenoso & 02 & 28,56 \\
Manutenção da fertilidade do solo & 02 & 28,56 \\
Para não ficar na dependência de apenas uma atividade & 02 & 28,56 \\
Necessidade de reforma das pastagens & 01 & 14,28 \\
Aproveitamento do tempo & 01 & 14,28 \\
A sustentabilidade financeira, agrícola e ambiental & 01 & 14,28 \\
Bem estar animal & 01 & 14,28 \\
Ganho de 10\% tanto de produção animal quanto de & 01 & 14,28 \\
massa & & \\
\hline
\end{tabular}

Fonte: Dados da pesquisa.

*Os Produtores relataram mais de um motivo

Os motivos apresentados pelos produtores foram confirmados com os benefícios alcançados após a adoção do sistema (Tabela 4).

Para o benefício mais citado, aumento da produtividade, utilizou-se como parâmetro sacas/ha e lotação/ha de animais em comparação ao sistema anteriormente adotado. Os resultados mais significativos foram constatados com os que produzem em solo de textura arenosa. No caso do produtor 1, houve uma variação por talhão com aumento de 10 até 25 sacas/ha (27\% a $70 \%$ de aumento) e um aumento na lotação animal de 1 para 5 animal/ha; para o produtor 4 esse aumento foi mais elevado, chegando até 30 sacas/ha (100\% de aumento) na maior parte dos talhões, e uma lotação de 1 para 5 animal/ha. Nos dois casos, o Sistema implantado foi o Agropastoril. O produtor 2, que tem implantado o Sistema Silvipastoril, enfatizou que em razão de não 
ter realizado reforma de pastagem, observou que a produtividade se manteve; segundo o produtor 3, além do Sistema Agropastoril proporcionar um aumento de 10 sacas/ha (20\% de aumento), constatou uma maior taxa de prenhes dos animais e a manutenção do peso também no período de estiagem. Esta última informação é igualmente compartilhada pelo produtor 6 que acrescentou ter um aumento da lotação de 1 para 3 animais/ha; já o produtor 5 pontuou que a produtividade da soja aumentou cerca de 3 a 5 sacas/ha (5\% a $10 \%$ de aumento) e a lotação animal ficou em torno de 7 animal/ha; no caso do produtor 7 , que relatou ter o ganho de $10 \%$ de produção animal e $10 \%$ em produção de massa (capim), além do bem-estar animal, como motivos da adoção do sistema, afirmou não ter realizado a medição da produtividade, mas percebeu uma melhora geral em relação ao Sistema anteriormente implantado, sendo o atual o Sistema Silvipastoril.

Tabela 4: Distribuição dos benefícios constatados após a adoção do Sistema iLPF em relação ao número de produtores entrevistados.

\begin{tabular}{lcc}
\hline Benefícios & $\mathbf{N}^{*}$ & $\%$ \\
\hline Aumento da produtividade & 05 & 71,40 \\
Maior rentabilidade econômica & 03 & 42,85 \\
Combate à erosão & 03 & 42,85 \\
Melhoria dos atrib. (físico, químico biológico) do solo & 02 & 28,56 \\
Produção de alimento para o gado no período da seca & 02 & 28,56 \\
Aumento da qualidade das pastagens (massa, nutrientes) & 02 & 28,56 \\
Cobertura do solo & 01 & 14,28 \\
Proporciona produção o ano todo & 01 & 14,28 \\
Retenção de umidade & 01 & 14,28 \\
Evita o aumento da temperatura do solo & 01 & 14,28 \\
Maior segurança na germinação das sementes & 01 & 14,28 \\
Maior segurança quanto aos investimentos & 01 & 14.28 \\
Intensificação do uso do solo & 01 & 14,28 \\
Diminuição do uso de fertilizantes e defensivos & 01 & 14,28 \\
Aumento da oferta de trabalho no campo & 01 & 14,28 \\
Engloba todas as dimensões de sustentabilidade & 01 & 14,28 \\
Aumento do bem-estar animal & 01 & 14,28 \\
\hline
\end{tabular}

Fonte: Dados da pesquisa

*Os produtores relataram mais de um benefício

Os dados apresentados mostram que os produtores conseguiram constatar na prática, após a adoção do Sistema, seus motivos iniciais de implantação.

Quanto aos resultados alcançados pelos participantes do estudo, Zimmer et al. (2012) pontuam que "dos 173 milhões de hectares de pastagens no Brasil, 117 milhões de hectares são de pastagens cultivadas, com uma lotação média de 1,2 animal/ha". E complementam que áreas em condições adequadas ou ótimas não ultrapassem os $20 \%$. 
“A qualidade das pastagens tem sido o grande desafio da pecuária" (MAGALHÃES e LIMA, 2014, p. 10), diante da problemática, a partir de 1980, a Embrapa e outras instituições de pesquisa têm intensificado a busca por soluções e a transferência de tecnologias para recuperação de pastagens com sistemas de integração (ZIMMER et al., 2012).

Muitas informações e benefícios apresentados pelos entrevistados são evidenciados nos resultados de pesquisas de Macedo (2009), Balbino et al. (2011), Vilela et al. (2011) no bioma Cerrado, Carvalho et al. (2011) na Região Sul do país com duração de 10 anos, também em estudos de Oliveira et al. (2015) na Região Amazônica e Assis et al. (2015).

No presente estudo, constatou-se a percepção dos participantes sobre os benefícios e as contribuições das dimensões tecnológicas, econômicas e ambientais da iLPF em relação às sociais, o que pode ocorrer por serem mais visíveis. De acordo com Balbino, Barcellos e Stone (2011), os benefícios sociais podem ser, entre outros, o aumento da oferta de alimentos de qualidade para a população; melhoria da qualidade de vida do produtor rural e sua família; fixação e ampliação da inserção social pela melhor distribuição de renda e maior geração de empregos no campo; redução do processo migratório e estímulo à qualificação profissional.

Observou-se que, o benefício, "mitigação do efeito estufa, resultante da maior capacidade de sequestro de carbono" (BALBINO, BARCELLOS e STONE, 2011, p. 35), que é o objetivo central do Plano $\mathrm{ABC}$, não fora relatado por nenhum dos sujeitos, o que sugere como já exposto, a baixa difusão do Plano $\mathrm{ABC}$ no estado, e/ou também por ainda estar mais fortemente presente a dimensão econômica em detrimento das demais dimensões sustentáveis propostas pela iLPF.

\section{Perspectivas e desafios para a implementação da iLPF em Mato Grosso}

Os produtores entrevistados demonstraram otimismo quanto ao futuro da iLPF no estado de Mato Grosso, confirmado nas falas:

As perspectivas são boas e muitos agricultores ainda devem aderir (Produtor 1).

É fundamental para o estado, porém tem que se respeitar a vocação do agricultor e a adequação a cada região (Produtor 2).

Vai acabar atingindo toda a pecuária do estado, pois na reforma do pasto é necessário esse tipo de tecnologia (Produtor 3). 
Se houver mudança de mentalidade do produtor rural e de todos os atores envolvidos [...] vejo boas perspectivas para a modalidade agropastoril. Não acredito que as atividades possam mais funcionar separadas (Produtor 5).

Tem que acontecer e é preciso um trabalho forte de todos os atores envolvidos para fortalecer o Sistema (Produtor 7).

Balbino, Barcellos e Stone (2011, p. 62) enfatizam que "a taxa de aceitação e adoção pelos proprietários rurais, [...] tem evidenciado que essa estratégia irá proporcionar avanços na agricultura nacional" e está sendo aplicada em maior ou menor grau de intensidade em todos os biomas brasileiros.

Os respondentes chamam a atenção para o fortalecimento dos envolvidos na implementação e observam suas próprias contribuições no processo, evidenciando a importante e necessária participação dos produtores rurais, uma vez que a iLPF só se efetivará se os objetivos forem compreendidos. Dessa forma, a implementação não pode ser impositiva, mas ser compartilhada por meio do conhecimento, de maneira que ambos os lados tenham a oportunidade de contribuir, seja de forma intuitiva ou científica.

No centro das perspectivas para a iLPF está o aumento do consumo mundial por alimentos, que segundo a ONU (2012) será para alimentar nove bilhões de pessoas até 2050, de bioenergia e produtos florestais (VILELA, MARTHA JUNIOR e MARCHÃO, 2012).

\begin{abstract}
A solução da complexa equação de aumentar a oferta de alimentos, respeitando as restrições impostas pelos fatores ambientais coloca-se como um dos principais desafios para a sociedade. Nesse sentido muito se tem investido e pesquisado com o propósito de encontrar alternativas sustentáveis para a produção de alimentos (REIS et al, 2016, p. 69).
\end{abstract}

Para os entrevistados, a iLPF é uma das alternativas capazes de integrar as ações que proporcionarão o enfrentamento dessa realidade. Enfatizam que houve avanços, com boas perspectivas de seu desenvolvimento em Mato Grosso, mas faz-se necessário sanar alguns entraves que dificultam sua implementação. Os produtores que aderiram ao Programa $\mathrm{ABC}$ citam o excesso de burocratização, bem como a falta de familiaridade dos agentes bancários em relação ao financiamento. A carência de assessores técnicos capacitados no estado e a falta de comunicação dos implementadores junto aos produtores rurais foram enfatizadas por todos os entrevistados.

Pode-se atribuir alguns dos fatos citados, em parte, à recente iniciativa de adoção da iLPF pelo estado de Mato Grosso, com a primeira Unidade de Referência Tecnológica (URT) para fins de pesquisa, validação e transferência de tecnologia implantada pela Embrapa na safra 2004/2005. No entanto o Observatório ABC (2013) 
afirma que a divulgação e a capacitação por meio do Plano ABC têm sido limitadas, devido às restrições tanto de pessoal, quanto de orçamentos, principalmente do Ministério da Agricultura, Pecuária e Abastecimento (MAPA) e do Ministério do Desenvolvimento Agrário (MDA).

Os respondentes complementam afirmando que um dos importantes desafios a ser superado é a articulação de todos os atores envolvidos na implementação, embora haja reconhecimento por parte de alguns que a iLPF é uma atividade relativamente nova no estado de Mato Grosso, o qual possui uma área territorial de grandes proporções, assim, não se pode esperar tanto dos implementadores, havendo a necessidade de cada produtor rural fazer a parte que lhe cabe nesse processo.

\section{Considerações Finais}

A pesquisa permitiu identificar que a percepção dos entrevistados se constrói, entre outros, a partir da influência de variáveis abordadas no estudo, como: o tempo e as experiências na atividade agropecuária; a condição de migrante, especialmente da região sul do país; a formação escolar, e o engajamento social por meio da participação em sindicatos, cooperativas e/ou outras associações. Essa vivência e conhecimentos adquiridos fornecem valiosas informações para a retroalimentação do processo de implementação, contribuindo com a ampliação e/ou redirecionamentos das estratégias de ação.

Constatou-se também que há um amadurecimento dos sujeitos quanto aos impactos negativos herdados pelo monocultivo. São percebidos em maior intensidade, os benefícios e contribuições econômicas, tecnológicas e ambientais da iLPF e, em menor intensidade, as sociais.

Em relação à obtenção de informações, os eventos organizados pela Embrapa e Sistema Famato, bem como outras associações citadas, especialmente na modalidade "Dia de Campo", se mostraram importantes e eficientes canais para a comunicação com o produtor rural. Este e os demais veículos de comunicação citados têm contribuído na tomada de decisão, fornecendo informações cada vez mais especializadas e de qualidade.

A pesquisa apontou ainda que os produtores se mostraram otimistas em relação à adoção da iLPF pelo estado de Mato Grosso. Enfatizam ser este um caminho viável, 
visualizando especialmente seus aspectos econômicos e ambientais, bem como apontam para alguns desafios a serem superados na implementação: dificuldade do acesso ao Programa ABC devido ao excesso de burocratização e falta de familiaridade dos agentes bancários; necessidade de aumentar o número de técnicos assessores capacitados no sistema, e comunicação deficiente dos implementadores junto aos produtores e articulação dos mesmos em relação à consolidação dessa política em Mato Grosso.

Faz-se necessário esclarecer que, pela extensa área territorial que cada região ocupa, pode ocorrer heterogeneidade em relação à implementação da iLPF dentro de uma mesma região.

\section{REFERÊNCIAS}

ABRAMOVAY, R. A atualidade do método de Josué de Castro e a situação alimentar mundial. Revista de Economia e Sociologia Rural, v. 3-4, n.1, p. 81-102, 1996.

AGUIAR, T. de J. A. de.; MONTEIRO, M. do S. L. Modelo agrícola e desenvolvimento sustentável: a ocupação do cerrado piauiense. Ambiente \& Sociedade, v. 8, n. 2, p. 161-178, 2005.

ASSIS, P. C. R.; STONE, L. F.; MEDEIROS, J. C.; MADARI, B. E.; OLIVEIRA, J. de M.; WRUCK, F. J. Atributos físicos do solo em sistemas de integração lavourapecuária-floresta. Revista Bras. Eng. Agríc. Ambiental, v. 19, n. 4, p. 309-316, 2015.

BALBINO, L. C.; BARCELLOS, O.; STONE, L. F. (Ed. técnicos). Marco referencial integração lavoura-pecuária-floresta. Brasília, DF: Embrapa, 2011.

BALBINO, L. C.; CORDEIRO, L. A. M.; PORFÍRIO-DA-SILVA, V.; MORAES, A. de.; MARTINEZ, G. B.; ALVARENGa, R. C.; KICHEL, A. N.; FONTANELI, R. S.; SANTOS, H. P. dos.; FRANCHINI, J. C.; GALERANI, P. R. Evolução tecnológica e arranjos produtivos de sistemas de integração lavoura-pecuária-floresta no Brasil.

Pesquisa Agropecuária Brasileira, v. 46, n. 10, 2011.

BARROS, G. S. C. Política agrícola no Brasil: subsídios e investimentos. In:

GASQUES, J. G.; VIEIRA FILHO, J. E. R.; NAVARRO, Z (Orgs). A Agricultura

Brasileira: desempenho, desafios e perspectivas. Brasília, DF: Ipea, p. 237-258, 2010.

BRANDENBURG, A. Ciências sociais e ambiente rural: principais temas e perspectivas analíticas. Ambiente \& Sociedade. n. 8, p. 51-64, 2005.

BRASIL. Lei n. 12.805, de 29 de abril de 2013. Institui a Política Nacional de Integração Lavoura-Pecuária-Floresta e altera a Lei n. 8.171, de 17 de janeiro de 1991. DOU de 30/04/2013. 
CAMARANO, A.; ABRAMOVAY, R. Êxodo rural, envelhecimento e masculinização no Brasil: um panorama dos últimos 50 anos. Rio de Janeiro: Ipea, 1999.

CARVALHO, A. F. de; MONTAÑO, M. A Integração de políticas públicas ambientais e o ordenamento territorial no Brasil. In: VI ENCONTRO NACIONAL da ANPPAS (GT 15). 2012, Belém. Anais [...] Belém: ANPPAS, 2012.

CARVALHO, P. C. F. et al. Integração soja-bovinos de corte no sul do Brasil. Porto Alegre: UFRGS, 2011.60p. (Boletim Técnico)

CONAB, Companhia Nacional de Abastecimento. Acompanhamento da safra brasileira de grãos. - Safra 2015/16 - nono levantamento / Junho 2016. v. 3, n. 9, Brasília: Conab, 2016.

CONAB, Companhia Nacional de Abastecimento. Acompanhamento da safra brasileira de grãos. - Safra 2020/2021- primeiro levantamento / outubro 2020. V. 8, n. 1, Brasília: Conab, 2020.

CUNHA, J. M. P. da. Dinâmica migratória e o processo de ocupação do Centro-Oeste brasileiro: o caso de Mato Grosso. Revista Brasileira de Estudos de População. v. 23, n.1, p. 87-107, 2006.

CUSTÓDIO, R. C. O mosaico da esperança: migração em Mato Grosso na segunda metade do século XX. In: FRANÇA, R.; BATISTA, I. M. (Orgs). Fronteiras de sonhos: migração, trabalho e política de identidade em terras mato-grossenses. Cáceres: Unemat, p. 37-54, 2015.

DI GIOVANNI, G. As Estruturas elementares das políticas públicas. Núcleo de Estudos de Políticas Públicas. Caderno de Pesquisa n. 82. Campinas: UNICAMP, 2009.

DIAS, R. Gestão ambiental: responsabilidade social e sustentabilidade. São Paulo: atlas, 2 ed., 2011.

EMBRAPA. Empresa Brasileira de Pesquisa Agropecuária. Projeto Transferência de Tecnologia em Sistemas de iLPF nos Estados de MT, GO e no DF. Brasília, DF: Embrapa, 2015.

GUIMARÃES, R. S. A construção democrática da Conferência das Nações Unidas Sobre Desenvolvimento Sustentável (Rio+20). Revista Jurídica, Anápolis, v. 2, n. 21, Ano XIII, p. 135-153. jul./dez. 2013.

IBGE. Censo populacional, 2010. Disponível em: https://cidades.ibge.gov.br/brasil/mt/panorama. Acesso em: out. 2015.

IBGE. Área territorial oficial, 2016. Disponível em:

http://www.ibge.gov.br/home/geociencias/areaterritorial/principal.shtm. Acesso em: jul. 2016.

IMEA. Instituto Mato-grossense de Economia Agropecuária. Composição do funding do custeio da soja para safra 2015/16 em Mato Grosso, 2015. Disponível em: 
http://www.imea.com.br/upload/pdf/arquivos/E040_Analise_da_nova_composicao_do_ funding_do_credito_agricola_do_Brasil.pdf. Acesso em: jun. 2016.

IMEA. Instituto Mato-grossense de Economia Agropecuária. Mapa de macrorregiões do Imea, 2016. Disponível em:

http://www.imea.com.br/upload/downloads/REGIOES_IMEA_MUNICIPIOS.pdf. Acesso em: jan. 2016.

IMEA. Instituto Mato-grossense de Economia Agropecuária. Composição do funding do custeio da soja para safra 2018/19 em Mato Grosso. 2018. Disponível em: http://www.imea.com.br/imea-site/view/uploads/relatoriosmercado/Funding_Soja_2018.pdf. Acesso em: nov. 2020.

MACEDO, M. C. M. Integração lavoura e pecuária: o estado da arte e inovações tecnológicas. Revista Brasileira de Zootecnia. v. 38, 133-146, 2009 (supl. especial). Disponível em: http://www.scielo.br/pdf/rbz/v38nspe/v38nspea15.pdf. Acesso em: jan. 2016.

MAGALHÃES, R. S. A "masculinização" da produção de leite. Revista de Economia e Sociologia Rural, v. 47, n. 1, p. 275-300, 2009.

MAGALHÃES, M. M. de; LIMA, D. A. L. L. Agricultura de baixo-carbono no Brasil: o impacto ambiental e comercial das atuais políticas agrícolas. Genebra: ICTSD, 54 ed., 2014.

MAPA. Plano setorial de mitigação e de adaptação às mudanças climáticas para a consolidação de uma economia de baixa emissão de carbono na agricultura : plano ABC (Agricultura de Baixa Emissão de Carbono). Coordenação da Casa Civil da Presidência da República. Brasília : MAPA/ACS, 2012.

MATO GROSSO. Decreto n. 2.052, de 18 de dezembro de 2013. Institui o plano estadual de agricultura de baixo carbono (Plano ABC/MT). Cuiabá: DOE de 19/12/2013.

MAZOYER, M.; ROUDART, L. História das agriculturas no mundo: do neolítico a crise contemporânea. (Claudia F. Falluh Balduino Ferreira - Trad.). São Paulo: Editora Unesp; Brasília, DF: NEAD, 2010.

MENDES, M. A. História e geografia de Mato Grosso. Cuiabá: Cafarnaum, 2012.

MINAYO, M. C. de S. Pesquisa social: teoria, método e criatividade. Rio de Janeiro: Vozes, 22 ed., 2003.

MORENO, G. Os (des) caminhos da apropriação capitalistas da terra em Mato Grosso. 620 f. São Paulo, Tese (Doutorado em Geografia) - USP, 1993.

OBSERVATÓRIO ABC. Propostas para revisão do Plano ABC, 2013. Disponível em: http://www.observatorioabc.com.br/propostas-para-revisao-do-planoabc?locale=pt-br. Acesso em: dez. 2015. 
OKAMOTO, J. Percepção ambiental e comportamento. São Paulo: Editora Machenzie, 2002.

OLIVEIRA, B. S.; CARVALHO, M. A. C.; LANGE, A.; WRUCK, F. J.;

DALLACORT, R. Atributos biológicos do solo em sistema de integração lavourapecuária-floresta na Região Amazônica. Engenharia na Agricultura, v. 23, p. 448456, 2015.

ONU. Conferencia das Nações Unidas sobre desenvolvimento sustentável, 2012. Disponível em: http://www.onu.org.br/rio20/temas-alimentos/. Acesso em: out. 2015.

PEREIRA, B. D.; MARTINS, V. F.; MENDES, C. M.; FARIA, A. M. de M.; SILVA, G. R. da. Reflexões sobre efeitos sociais da modernização da agricultura de Mato Grosso. Revista de Estudos Sociais, v. 8, n. 1-2, 2006.

REIS, J. C. dos; RODRIGUES, R. de A. R.; CONCEIÇÃO, M. C. G. da; MARTINS, C. M. S. Integração Lavoura-Pecuária-Floresta no Brasil: uma estratégia de agricultura sustentável baseada nos conceitos da Green Economy Initiative. Sustentabilidade em Debate, v. 7, n. 1, p. 58-73, 2016.

RODRIGUES, M. R.; MALHEIROS, T. F.; FERNANDES, V.; DARÓS, T. D. A percepção ambiental como instrumento de apoio na gestão e na formulação de políticas públicas ambientais. Saúde e Sociedade, v. 21, n. 3, p. 96-110, 2012.

SÁNCHEZ, R. O. Zoneamento agroecológico do Estado de Mato Grosso:

ordenamento ecológico-paisagístico do meio natural e rural. Cuiabá: Secretaria de Estado de Planejamento e Coordenação Geral, 1992.

SILVA, C. B. de C.; SCHNEIDER, S. Gênero, trabalho rural e pluriatividade. In: SCOTT, P.; CORDEIRO, R.; MENEZES, M. (Orgs). Gênero e geração em contextos rurais. Florianópolis: Ed. Mulheres, p. 183-207, 2010.

SILVA, J. I. A; ALCÂNTARA, M. G. Políticas Ambientais: uma análise do Governo Federal e do Cariri Ocidental. Revista Politicas Públicas, São Luís, v. 19, n. 1, p. 281301, jan/jun. 2015.

SIMÕES, E. A. Q.; TIEDEMANN, K, B. Psicologia da percepção. São Paulo: EPU, 1985.

STEAD, D.; MEIJERS, E. Spatial planning and pollicy integration: concepts, facilitators and inhibitors. Planning Theory \& Practice, v. 10, n. 3, p. 317-332, 2009.

SWAIN, T. N. Fronteira do Paraná: da colonização a migração. In: AUBERTIN, C. (Org). Fronteiras. Brasília: EDU - UNB; Paris: ORSTOM, 1988.

TILMAN, D.; CASSMAN, K. G.; MATSON, P. A.; NAYLOR, R.; POLASKY, S. Agricultural sustainability and intensive production practices. Nature, v. 418, p. 671677, 2002. 
VILELA, L.; MARTHA JUNIOR, G. B.; MACEDO, M. C. M.; MARCHÃO, R. L.; GUIMARÃES JUNIOR, R.; PULROLNIK, K.; MACIEL, G. A. Sistemas de integração lavoura-pecuária na região do cerrado. Pesquisa Agropecuária Brasileira, v. 46, n. 10, p. 1127-1138, 2011.

VILELA, L.; MARTHA JUNIOR, R. G. B.; MARCHÃO, R. L. Integração lavourapecuária-floresta: alternativa para intensificação do uso da terra. Revista UFG, v. 8, n. 13, p. 92-99, 2012.

ZIMMER, A. H.; ALMEIDA, R. G. de; BUNGENSTAB, D. J.; KICHEL, A. N.; Integração lavoura-pecuária-floresta no Brasil: histórico e perspectivas para o desenvolvimento sustentável. In: VII CONGRESSO LATINOAMERICANO DE SISTEMAS AGROFLORESTAIS PARA A PRODUÇÃO PECUÁRIA

SUSTENTÁVEL. 2012, Belém. Anais [...] Belém: 08 de nov., 2012.

Recebido em: 2021

Aprovado em: 2021

Publicado em: 2021 